\title{
Astrophysics at the Royal College of Science*
}

\section{Tribute to Prof. A. Fowler}

$\mathrm{F}^{\circ}$ OR more than fifty years Prof. Fowler has been associated with the work of this College. For the greater part of that time he has been one of its leading figures; and now the time has come for that long association to cease. On such occasions as this it is customary-and it is well-to practise some dissimulation. If we were to express the feelings that lie nearest our hearts, we should not feast, but fast :

\section{"Make dust our paper, and with rainy eyes Write sorrow on the bosom of the Earth."}

But the age of realism in such things has yet to come. If the future is dark, we look towards the past and draw comfort from the thought that much that has been done survives and will survive in the days to come. In the career of Prof. Fowler there is special warrant for that reflection. When we look back at the long history of things of great value done supremely well, we are not only assured of their permanence; we are also held by the romance of their achievement.

We of this generation are inclined to look upon the period about the year 1895 as marking the renaissance of physical science from a state of stagnation-a state in which, as it has been said, it seemed that nothing remained to be done but to add a few more decimal places to the values of well-determined constants. That is not altogether a true picture. In the mind of one man, at least, the morning twilight of the new day shed its light long before the sun rose. At the Normal School of Science, which we are proud to claim as our ancestor, Norman Lockyer was making those researches into spectrum analysis and building those seemingly fantastic theories which to his contemporaries were either stumbling-blocks or foolishness, according to their nature, but which we recognise as the authentic herald of the physics of to-day. Lockyer could not convince the mature, but he could inspire the young; and in 1882 there came to his lectures a very young student, with more than ordinary ability, with all the enthusiasm of youth, and with the potentialities of a boundless loyalty waiting to be claimed. The sequel was inevitable. Lockyer was not only a pioneer in science, he was also an organiser of the first order ; and to that genius which gave the world its foremost scientific journal came its other great inspiration. In 1886, Alfred Fowler became computer to Prof. Lockyer.

It was my privilege a few years ago to be given access to Lockyer's papers. The name of Fowler does not often appear, but when it does the references are significant. "My excellent assistant Mr. Fowler." "Mr. Fowler did his eclipse work admirably." Whenever a piece of research depended on a crucial observation, that observation was invariably Mr. Fowler's. In scanning the records one became conscious of a dim. Presence haunting the background, always ready to interpose at the difficult minute-the sort of figure of which legends are made, like some shadowy Siegfried supporting the arms of the visible hero.

In the year 1901, Lockyer retired from the Royal College of Science, taking his laboratory equipment

* From a speech by Dr. H."Dingle at a complimentary dinner to Prof. A. Fowler, at the Imperial College Union, on Oct. 9 (see NATURE, Oct. 13, p. 562). with him into the Solar Physics Observatory, of which he retained the directorship, and Mr. Fowler was left in charge of what astrophysics remained in the College. To one who knows the Astrophysics Department only as it is to-day, its beginning at that time is scarcely credible. Mr. Fowler's laboratory was a table in a frequently used lecture theatre, in a corner of which a dark room had somehow to be improvised. For apparatus he had one small spectrograph, of a type which we should now consider suitable for a promising child's stocking at Christmas ; and for encouragement the collected indifference of most of those who might have been concerned. In such circumstances was begun that remarkable series of researches which lie at the basis of modern physical astronomy-the identification of the bands in the spectra of red stars; the detection of magnesium hydride and other compounds in sunspots; the solution of the problem of comet-tail spectra; the laboratory production of 'cosmic hydrogen'; and the many contributions to the experimental foundation of spectroscopy which have made our Astrophysics Department a goal of pilgrimage from all the continents of the earth. All the world knows these things; but he only knows the difficulties and the disappointments that beset their accomplishment.

My own acquaintance with Prof. Fowler began in the early days of the War, when his supremacy in all branches of spectroscopy was already established, and the new Bohr theory was making it manifest to all. To me, as a student, he was a great man by natural right. $\mathrm{He}$ belonged to the hierarchy of professors, who had not experienced the difficulties of us lesser minds, but had always lived aloft in inaccessible greatness. You can imagine my surprise when he came into the laboratory and joined in the elementary instruction, turning globes and adjusting spectroscopes with more skill and almost as much assurance as a first-year demonstrator. He didn't shirk questions : he invited them ; and the familiarity with the workings of Nature which he showed led us to sympathise with the error of the young lady who construed the arrow with the word "Wind" on the driving-clock of the telescope as his instruction to the wind to blow that way.

One of his rare errors of judgment occurred just after the War, when he asked Prof. Callendar for my services as demonstrator. There was no com. petition, and the request was granted. Another junior member of the staff said to me : "Why are you going into astrophysics? That's a side-line. You would do better to stick to general physics, and keep out of that narrow groove." But for my part I was pleased. The subject certainly had attractions, but to me it was not so much astrophysics as Fowler's Department that I was entering; and I soon found that, so far from entering a narrow groove, I was receiving a more than liberal education. We were a centre to which men of all types converged -astronomers with impossible theories to be made plausible; archæologists with specimens to be tested to discover whether the Sumerians could make bronze; nurses asking if their foods contained enough vitamins to build bonny babies; psychologists looking for differences between the spectra of human 
and animal souls: we were an encyclopædia for poets searching for spectroscopic metaphors; a hospital for ideas battered by the shocks of criticism ; a home for the consolation of lost causes and the triumph of successful ones: people of all trades, professioñs, races, nationalities, sexes, ages, religionsgreat men, small men, lean men, brawny men, brown men, black men, grey men, tawny men, grave old plodders, gay young friskers-all came for advice to this narrow specialist, and went away, if not always satisfied, at least convinced that nothing further could be done along that line.

All this is now ended, but we have one consolation, and a great one. When Persephone was taken by Pluto from the fields of Enna into the shades below, she was permitted to return once a year for the comfort of those who were left behind. Prof. Fowler is not going into the shades : he is leaving the visible spectrum, but there is a whole octave of ultra-violet to be traversed before the vacuum region is reached. And whatever god presides over the land in which he chooses to dwell, he goes on the condition that, not merely once a year, but whenever instinct tells him that he is needed, he is to be allowed to revisit the glimpses of the arc and the spark and the vacuum tube; and I for one shall listen daily for the familiar footstep. When it comes a drawer will be opened, and out will come the problems and the difficulties that have been put aside to await the coming of the master.

\section{Fluorescence Microscopy and its Application to the Identification of Fibres}

$\mathrm{O}^{\mathrm{m}}$ $\mathrm{NE}$ of the most recent and interesting applications of ultra-violet light as a testing method is its use as an aid to microscopical work. Since it is well known that structures visible to the naked eye show distinguishing features in ultra-violet light which are invisible in ordinary light, it is not unnatural that the application to microscopic structures of the same principle should have been attempted. As already indicated ${ }^{2}$, this method has met with considerable success, notably in the examination of sections of botanical specimens such as seeds, tissues, etc., the best results being obtained in cases where the individual details of the structure fluoresce differently. Starch and fatty matters, for example, fluoresce vividly and stand out in sharp contrast, and a notable case is that of cacao, in which the shell tissues and mucilage cells may be distinguished in this way.

The method has now been carried a stage further by the use of fluorescent materials as stains, and this has opened up many promising lines of advance in microscopical technique. It is obvious that if the dyes used for selective staining in ordinary microscopical work are supplemented by substances which cause a particular detail of the structure to fluoresce with a specific colour in ultra-violet light, then many strings will be added to the bow of the practical microscopist. Fortunately a large number of such substances (usually dyes) exist, and only await investigation.

The apparatus required for this work is by no means elaborate. A good microscope and a source of ultra-violet light are of course essential, and in connexion with the latter there seem to be differences of opinion among various workers as to which type gives the best results. All would probably agree, however, that a brilliant point source is desirable, so that the mercury vapour lamp in the form most familiar to workers in Great Britain is by no means the ideal. Successful results have, however, been obtained with arcs struck between iron, cadmium, magnesium-carbon and nickel-carbon electrodes.

The lens system on the arc side should be made of quartz on account of the absorbing powers of ordinary glass for ultra-violet light. This applies to the converging lens and condenser used to concentrate the light on the microscope mirror, and in addition it is desirable to insert filters to remove visible and infrared rays, so that the radiation finally obtained covers the range $3,000-4,000 \mathrm{~m} \mu$. Numerous commercial filters are available for the former purpose, and for the latter a cell containing a solution of copper sulphate is very convenient. Since the microscope is used only for the observation of effects produced by visible light, ordinary glass lenses may be used, and if the fluorescence is sufficiently bright, these are satisfactory even for colour photography.

Useful adjuncts in this work are devices for darkground and surface illumination. The Lieberkuhn mirror and other lens systems used for the latter purpose give very striking results which are quite different from those obtained by transmitted light; the self-luminosity of fluorescent structures also enables vivid effects to be obtained with dark-ground illumination. In some cases, it is an advantage to bed the specimen in a mounting medium, and the selection of the medium should be then governed by the nature of the specimen. Thus both Canada balsam and paraffin wax themselves fluoresce, but whilst in some cases the emission of light masks the fluorescence of the structure, in others it may be used to throw dark structures into relief. A speck of quinine placed on the slide is a great aid in focusing, as it is highly fluorescent.

Even under the above conditions, a certain amount of ultra-violet light may still reach the eye, and it is therefore advisable for prolonged work to wear protecting goggles in order to avoid the possibility of conjunctivitis. Special cover-slips which are opaque to ultra-violet light are an additional precaution and serve the further purpose of eliminating any fluorescence produced by the action of the rays on the lens system. For work with transmitted light, a quartz prism or a silver reflector is used in place of the microscope mirror, and the slide must, of course, be made of quartz; glycerol should replace cedar wood oil for 'oil' immersion lenses.

Some of the most interesting advances in this work have been made in connexion with fibre analysis, and in particular with that branch of the subject which is the concern of the cellulose industries. A number of ordinary stains are already in continual use in this connexion, but they suffer from several deferts, notably that they are difficult to prepare in a sensitive form, and that their applications are limited. F. Noss and H. Sadler ${ }^{2}$, however, have examined the suitability of a large number of dyes from the point of view of fluorescence microscopy, and find that in particular, a 0.05 per cent solution of rhodamine -6 G-D has useful properties. Thus, fibres prepared by the sulphite process appear yellow, whilst' sulphate pulps give an orange-red colour; if the fibres have not been bleached the colours assume a brown tinge. Since the vivid blue fluorescence of unstained, unbleached wood fibres is a well-known phenomenon, 